\title{
Wear Prediction in Oscillating Cold Forging Processes
}

\author{
Peter Groche ${ }^{1}$. Wilhelm Schmidt ${ }^{1}$ (1)
}

Received: 13 July 2020 / Accepted: 27 October 2020 / Published online: 10 November 2020

(c) The Author(s) 2020

\begin{abstract}
Oscillating forming processes allow forming with reduced process forces when liquid lubricants are used. They are industrially applied as oscillating cold forging processes for the production of splines. Previous investigations revealed that the force reduction is provoked by relubrication of the workpiece- tool contact zone. So far, the effect of the oscillation on tool wear remains unknown. The results presented in this paper show that the wear critical region of the tool is the calibration zone. Tool wear is emulated on a test bench under loads of representative cold forging processes. The results disclose several relevant phenomena. Friction conditions can vary considerably in the course of the oscillations. Wear protection layers are effective measures to prolong tool life also under these conditions. Prediction of wear development based on established models fails due to neglecting the local state of lubrication.
\end{abstract}

\section{Graphical Abstract}
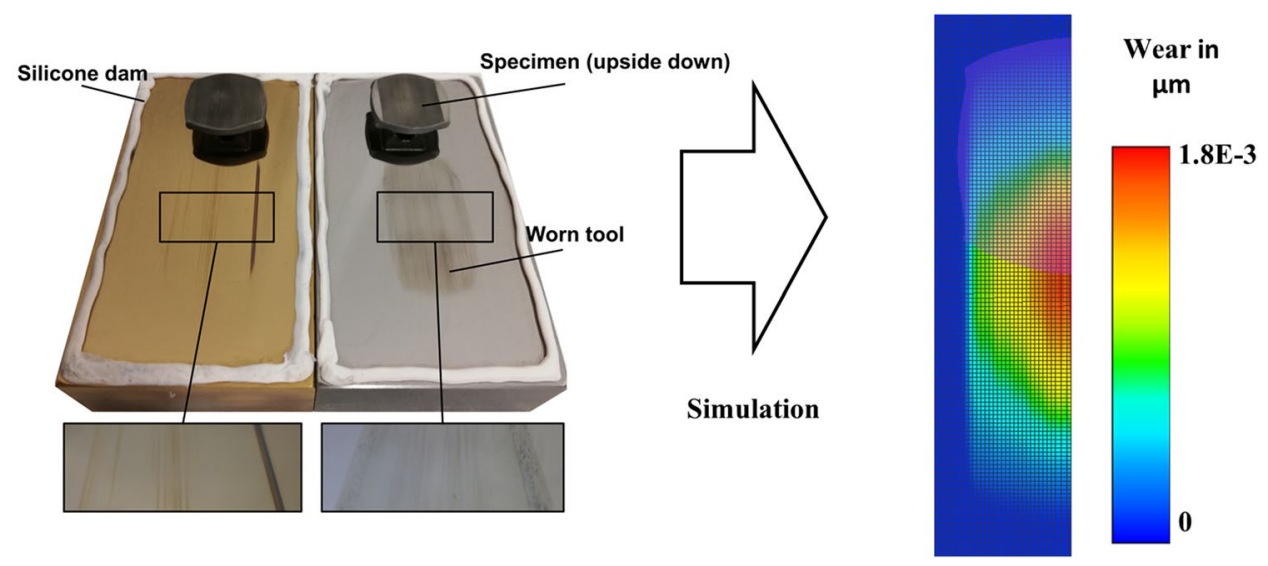

Keywords Abrasive wear $\cdot$ Adhesive wear $\cdot$ Wear mechanisms $\cdot$ Cold forging $\cdot$ Oscillating forming

\section{Introduction}

Cold forging technologies are industrially applied for a cost-effective large volume production of high-quality components [1]. Product quality and economic efficiency of these processes depend on the tool life. Both are improved

Wilhelm Schmidt

wilhelm.schmidt@ptu.tu-darmstadt.de

1 Institute for Production Engineering and Forming Machines, Technische Universität Darmstadt, Darmstadt, Germany by reduced wear and better predictability of the wear development.

Various general wear theories have been proposed and applied to forming technologies. These wear theories assume unidirectional relative movements between the contact partners. With respect to new motion controls in metal forming [2], the influence of other forms of relative movements on the tool wear development is of high interest.

Several studies focus on the advantages of oscillating tool movements. The reduction of forming forces and the increase of the accuracy due to oscillating movements 
Fig. 1 Exemplary industrial motivated specimen. Spline length: $40 \mathrm{~mm}$

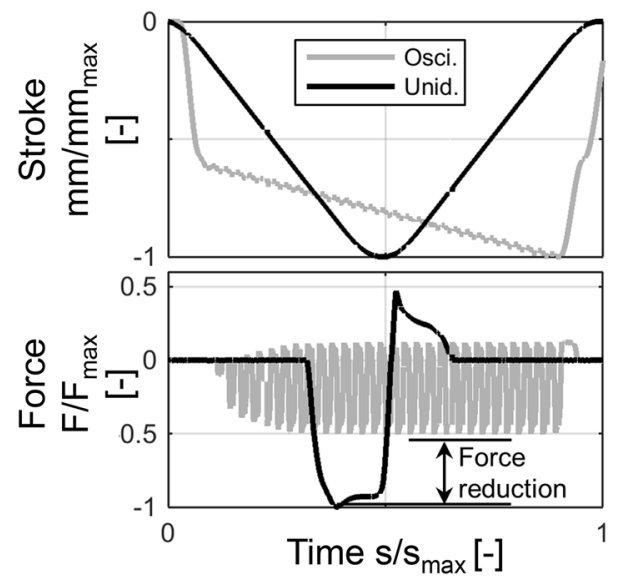

Fig. 2 Stroke (top) and forming force (bottom) for oscillating and unidirectional ram movement in oscillating gear forming [11]

during upsetting operations are investigated by Maeno et al. $[3,4]$. A relubrication effect causes the force reduction in this process. The same effect is described by Maeno et al. [5] and Matsumoto et al. [6] to prevent seizure during backward extrusion operations. Landgrebe et al. show that a deeper draw or more complex geometries are suitable using cushion-ram pulsation in hot stamping operations [7].

Besides extrusion and forging operations, an indentation operation with superimposed oscillations is used to reduce the forming forces by $40 \%$ [8]. For industrial applications oscillating movements are used during gear forming processes. Typically manufactured components are splines. The industrial motivated specimen in Fig. 1 was produced with a $3 \mathrm{~mm}$ forward and $1.5 \mathrm{~mm}$ return stroke. There is no rotation during the forming process. The average forming speed is $20 \mathrm{~mm} / \mathrm{s}$.

The achievable force reduction provides the capability to form gears on hollow shafts without exceeding the buckling
Contact normal stress of the work piece
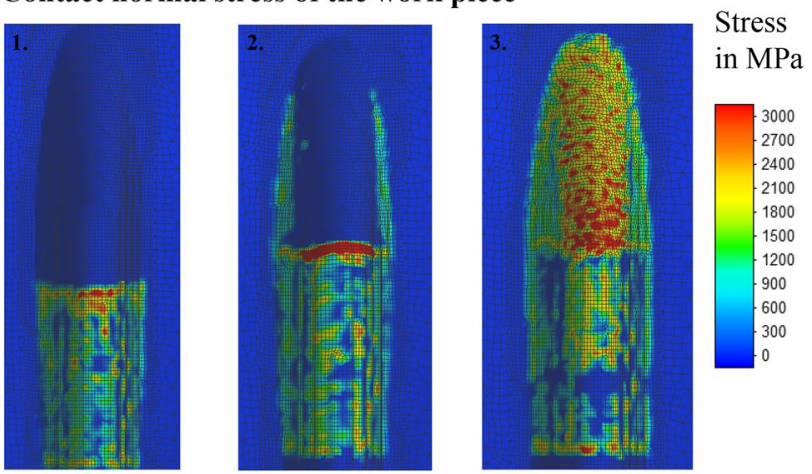

1. Return stroke 2. Start Forward stroke 3. Forward stroke

Exemplary tool wear

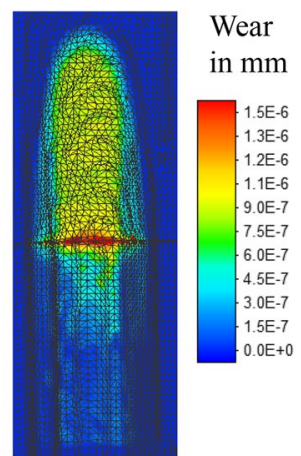

Fig. 3 Numerical simulation of the contact normal stress on the work piece and the tool wear of an exemplary tool. Material flow from top to bottom

stability. Stroke and forming forces of the part, shown in Fig. 1, for an oscillating and a unidirectional gear forming process are shown in Fig. 2.

Recent studies $[9,10]$ identify the relubrication of the forming zone during the return stroke as reason for the force reduction. Therefore, the process takes place under continuous oiling.

The prediction of wear is particularly difficult for oscillating forming processes because the contact conditions on the individual tool areas are alternating discontinuously.

Especially, the contact normal stress occurs in a discontinuous way. Figure 3 shows the stresses of a tool in the return stroke and in the forward stroke. It can be seen that different areas are created in which the contact between workpiece and tool is partly lost (forming zone), and in which permanent contact exists (calibration zone).

Consequently, the wear prediction based on established wear theories like from Archard [12] and Rabinowicz [13] is questionable in this case.

Usually, the most pronounced wear of the gear forming tool can be found at the end of the calibration zone and not in the forming zone (see Fig. 4). 


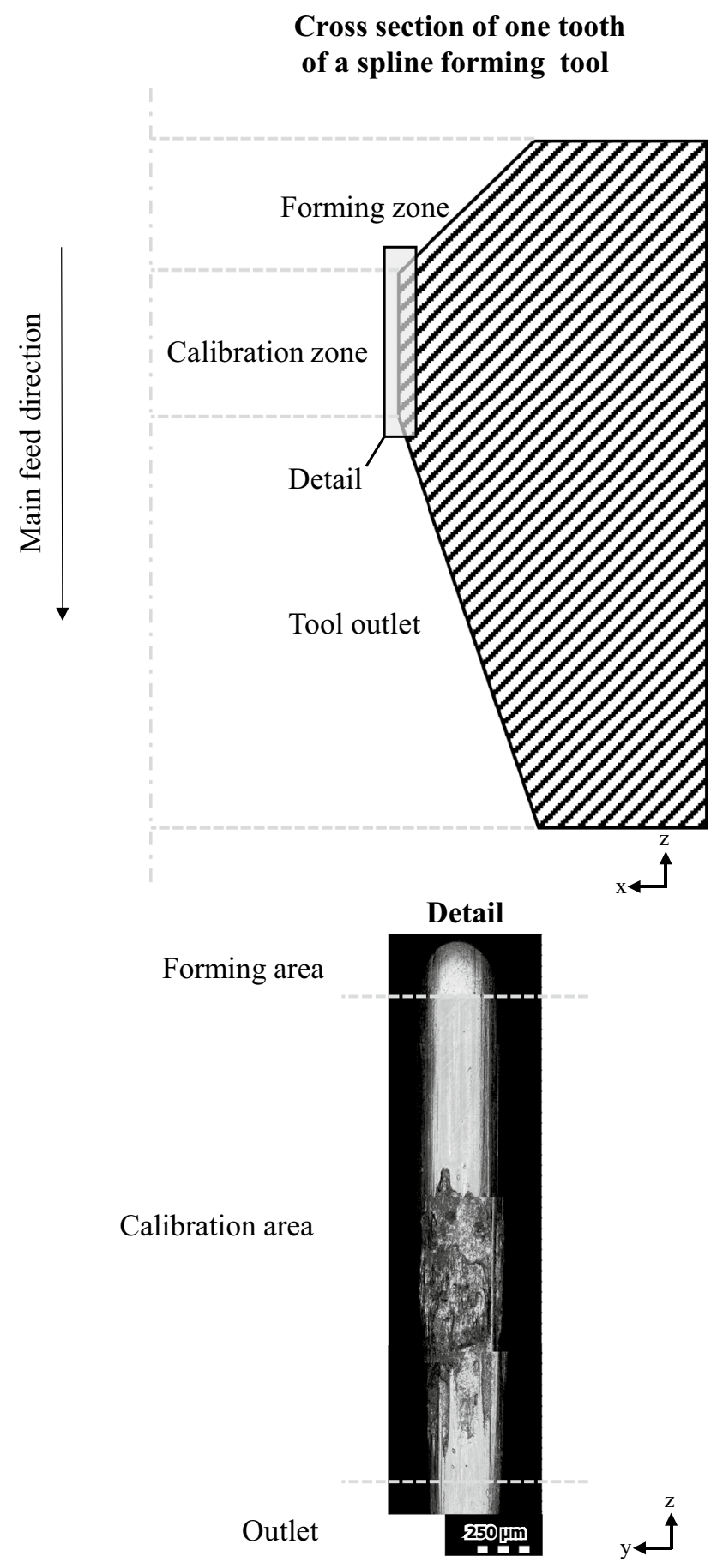

Fig. 4 Top: Tool areas. Bottom: Wear of an industrially used tool

This is surprising, as the higher contact normal stress is expected in the forming area.

Wear usually occurs when an abrasion of the coating occurs first. Material then starts to adhere at this point. In Fig. 4 both, slight abrasion and adhesion, can be observed. If the production would be continued with this tool, it would come to a complete collapse of the tool. In this case, the tooth would break off gradually.

The question arises whether the wear at the calibration zone can also be simulated in laboratory tests and predicted by simulations. Furthermore, a more detailed understanding of the wear causes is required. In order to answer the questions a special tribometer is used together with commercially available simulation software to question the wear theory.

\section{Wear Theory}

Several models describe occurring wear phenomena. In the field of forging, Archard's wear model (1953) is particularly popular. It presumes that the wear volume $W_{\mathrm{V}}$ depends on the contact normal force $F_{\mathrm{N}}$, the sliding distance $\mathrm{x}$ and the hardness $H$, see formula 1 [12]. The parameter $k_{\mathrm{V}}$ represents the wear factor and comprises all specific wear properties of the system.

$W_{V}=\frac{k_{V} F_{N} x}{H}$

Rabinowicz [13] and Holm [14] propose models that are formally identically to formula 1 [15]. They only deviate by the parameter $k$. Rabinowicz' model is used for abrasive wear and Holm's model is used for atomic wear [15]. Since the formal description is the same, the Archard model with an adapted $\mathrm{k}$ value for abrasive wear is used in this paper.

Formula 1 can also be expressed in integral notation. This form is used in various software implementations [16]. In contrast to the notation given in (1), this form does not determine wear as a volume, but as a wear depth.

$W_{D}=\int \frac{k_{D}}{H} \sigma\left|v_{r e l}\right| d t$

Under the assumption that the variables speed, contact normal stress and hardness are constants, (2) can be formulated as:

$W_{D}=\frac{k_{D}}{H} \sigma|x|$

In an oscillating process, the distances $|x|$ in the forward and return strokes are included in the calculation, provided there is contact between the friction partners in both strokes. During oscillating gear forming, permanent contact is only present in the calibration zone.

In this paper, this notation is used. Hardness is a state parameter that is not variable. The speed is adapted to the industrial process during the forward- and the return stroke. The contact normal stress in the calibration zone is also quite 


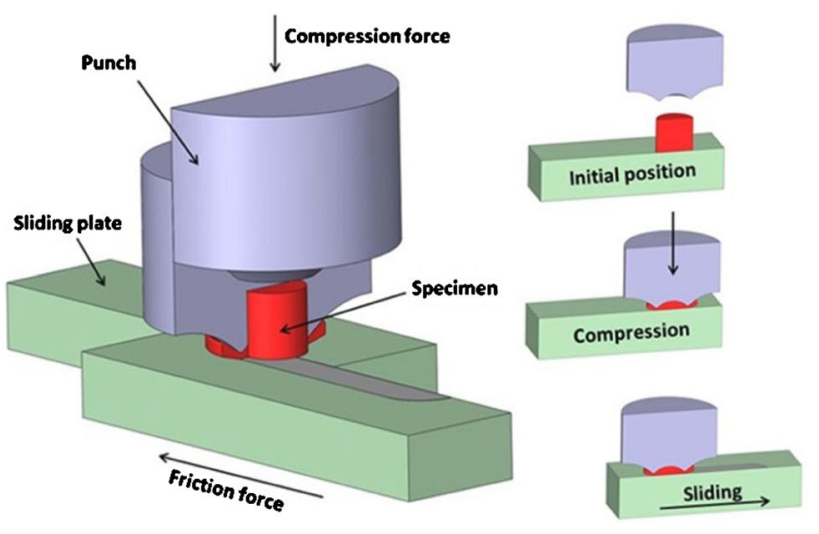

Fig. 5 Sliding Compression Test [22]

constant as only the calibration operation is carried out in this area during the entire production time, independent of forward and return stroke. For the forming zone, the mean contact normal stress at the forward stroke can be determined from the simulation. The contact length for the forming zone is defined by the forward stroke.

Since the information regarding the spatial distribution of wear over the surface is not integrated in Archard's equation, the growth of wear on the surface is monitored additionally.

\subsection{Test Setup}

To analyze tribological conditions in cold forging processes, the Sliding Compression Test (SCT) is used. This tribometer can reproduce tribological loads of cold forging operations such as contact normal stresses up to $3000 \mathrm{MPa}$, surface enlargement up to 11 and relative sliding velocities up to $500 \mathrm{~mm} / \mathrm{s}$. The SCT was developed to realize a nearly homogeneously distributed contact normal stress and surface enlargement [17]. This differentiates the SCT from other tribometers such as the Double Cup Extrusion Test [18], the Ring Compression Test [19] or the Spike Test [20]. Results derived from the SCT are in good quantitative agreement with results gained with other tribometers [21].

As shown in Fig. 5, the SCT is divided into two steps. In the first step, a usually cylindrical specimen is compressed. The specimen can be placed in a horizontal or vertical position for this purpose. For the investigations in this paper the horizontal position is chosen to adjust the contact normal stress. Due to the compression, the desired surface enlargement and contact normal stress are reached. In the second step, the sliding plate conducts a preset movement with a certain velocity, while the compression force remains constant. To determine a friction coefficient, the compression and the sliding forces are monitored. According to Coulomb's law, the friction coefficient can be calculated by the
Table 1 Experimental details for the sliding compression test

\begin{tabular}{ll}
\hline Parameter & Value \\
\hline Specimen height & $15 \mathrm{~mm}$ \\
Specimen diameter & $15 \mathrm{~mm}$ \\
Specimen material & $16 \mathrm{MnCr} 5(1.7131)$ \\
Tool material & X $155 \mathrm{CrVMo} 121(1.2379)$ \\
Lubricant & Multidraw CF4 (Zeller + Gmelin) \\
Viscosity & $41 \mathrm{~m} / \mathrm{s}^{2}$ at $40^{\circ} \mathrm{C}$ \\
Sliding distance & $60 \mathrm{~mm}(\mathrm{sum}$ of forward and return stroke) \\
Sliding velocity & $20 \mathrm{~mm} / \mathrm{s}$ \\
Compression force & $450 \mathrm{kN}$ \\
Specimen position & Horizontal \\
\hline
\end{tabular}

division of the friction force $\left(F_{\mathrm{R}}\right)$ and the compression force $\left(F_{\mathrm{N}}\right)$ :

$\mu=\frac{F_{R}}{F_{N}}$

The usual test sequence is modified to depict wear in the sliding compression test: after a single compression of a specimen, the specimen is repeatedly moved back and forth on the sliding plate. The force remains constant at the same level as during the forming process. This corresponds to the conditions in the calibration zone.

The tool is completely covered with oil to model the full lubrication state of the process. For this purpose, the tool sliding plate is surrounded by a silicone dam (see Fig. 8) and the area inside is filled with oil.

The specimens used in the SCT are made of $16 \mathrm{MnCr} 5$ with a diameter of $15 \mathrm{~mm}$ and a height of $15 \mathrm{~mm}$. One sliding plate (tool) is coated with a TiN PVD layer. The surface condition of both tools corresponds to a polished surface finish. In the event of interruptions for wear checks, the tools are cleaned and provided with new oil. The investigation of the wear is carried out by a confocal microscope

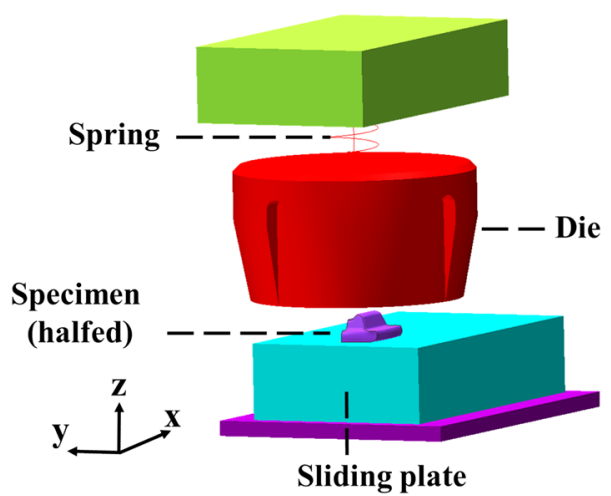

Fig. 6 Model in Simufact.Forming 15.0 

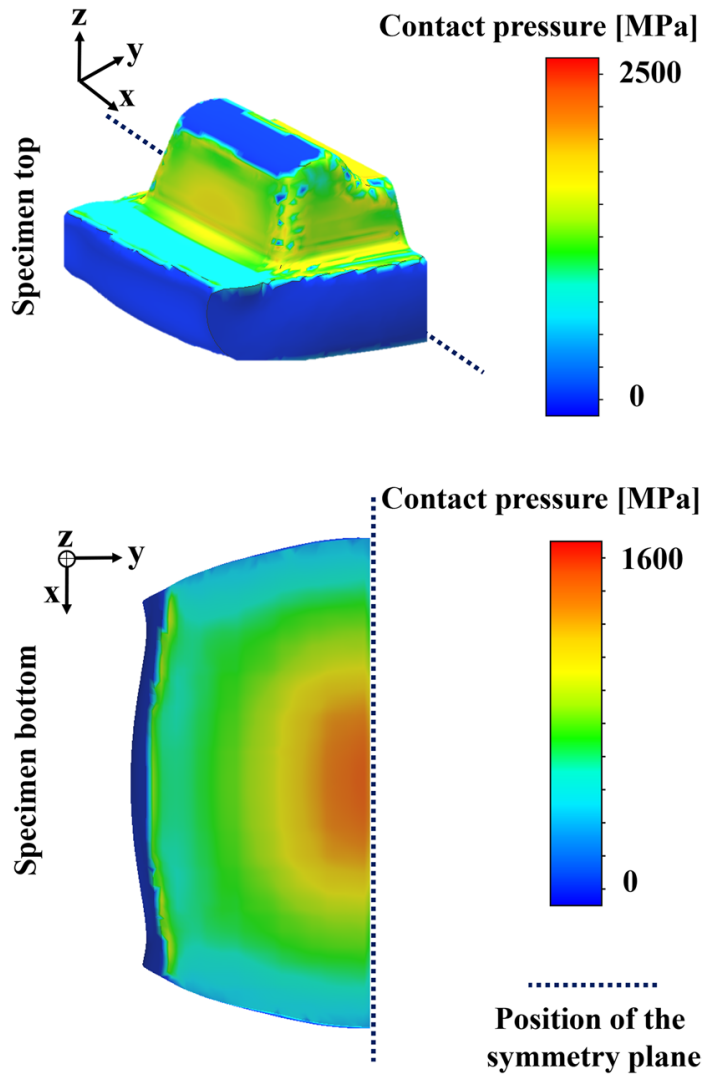

Fig. 7 Sample and simulated geometry (half symmetric model)

Table 2 Parameter for the SCT simulation

\begin{tabular}{ll}
\hline Parameter & Value \\
\hline Specimen material & $16 \mathrm{MnCr} 5$ (1.7131) \\
Friction coefficient & 0.07 \\
Oscillating stroke (Absolute movement of the & $30 \mathrm{~mm}$ (forward) \\
center of the specimen) & $30 \mathrm{~mm}$ (back- \\
& ward) \\
Stroke velocity & $20 \mathrm{~mm} / \mathrm{s}$ \\
Force & Constant $450 \mathrm{kN}$ \\
Average stress & $1050 \mathrm{MPa}$ \\
Element size specimen $\mathrm{x}, \mathrm{y}, \mathrm{z}$ dimension & $0.3 \mathrm{~mm}$ \\
Element size sliding plate $\mathrm{x}, \mathrm{y}, \mathrm{z}$ dimension & $0.5 \mathrm{~mm}$ \\
Element type & Hexahedron 8 \\
& noded, 8 point \\
& Gauss integra- \\
Solver & tion \\
\hline
\end{tabular}

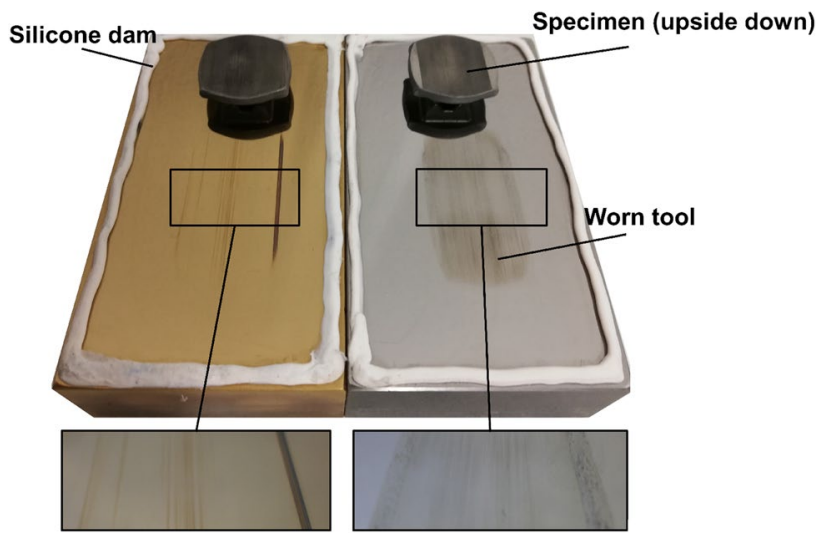

Fig. 8 Tool surfaces after the experiments. Left: TiN-coated sliding plate (tool); Right: Uncoated sliding plate

( $\mu$ Surf expert) and a digital microscope (Zeiss Smartzoom 5). Applying the material $16 \mathrm{MnCr} 5$, the compression force of $450 \mathrm{kN}$ is used.

The velocity, lubricant, and force are relative to the conditions in the calibration zone (see also Fig. 3, 4) of an oscillating gear forming process. The experimental details are summarized in Table 1.

\subsection{Numerical Setup}

The sliding compression test is simulated with the Finite Element code simufact.forming 15.0.

Figure 6 shows the simulation model. In the first step, the contact force is applied on the specimen (purple) via the die (red). Afterwards, the turquoise sliding plate is moved in horizontal direction. After $30 \mathrm{~mm}$, the movement turns until the initial position is reached again. The specimen and the sliding plate are modeled as deformable bodies, while the other parts are rigid. As contact condition between both bodies the friction $\mu=0.07$, which is determined using the $\mathrm{SCT}$, as well as the respective hardness value and $k_{\mathrm{D}}$ factor are assigned. Since the force is controlled by the machine during the SCT, this process is implemented in the simulation by a spring. This ensures that the force of $450 \mathrm{kN}$ is kept constant throughout the entire test period. The sample (purple) is only half side simulated because of the symmetric geometry. The sliding process is simulated for one forward and one backward stroke.

The contact normal stresses acting on the specimen can be found in Fig. 7. The parameters of the numerical simulation are presented as an overview in Table 2. 


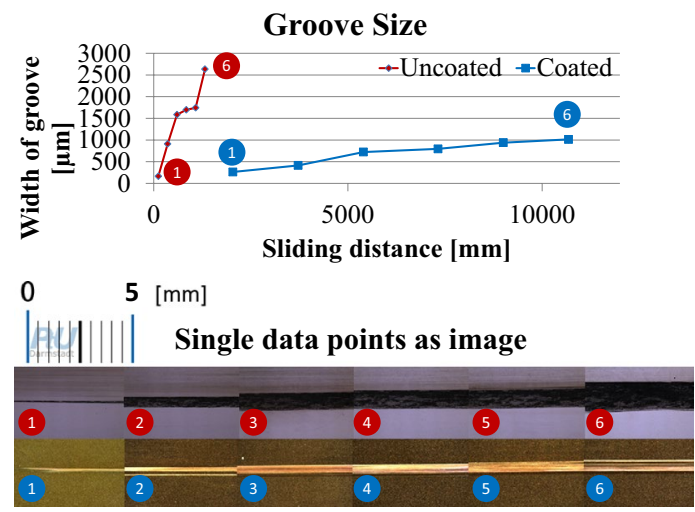

Fig. 9 Groove width on coated and uncoated tool. Each measured groove is shown as an image below

\section{Experimental Results}

During the tests, wear can be observed on the coated and the uncoated tool. The wear of the uncoated sliding plate occurs much faster than on the coated sliding plate.

The uncoated tool is inspected every 4th stroke. The first pass is interrupted because wear is already visible after 2 strokes. Inspections of the coated tools take place every 12th stroke. This is necessary in order to complete the tests promptly, without overheating the hydraulic press. If additional wear is noticeable, pictures are taken and the oil is replaced. For the coated tool, this occurs after 36, 62, $90,122,150$, and 187 strokes. For the uncoated tool, this occurs after 2, 6, 10, 14, 18 and 22 strokes.

The location of wear can be seen in Fig. 8. It can be found on the uncoated sliding plates in the outer regions of the contact area between sample and plate. For the coated plate, it can additionally be found in the middle of the contact area. The wear is visible nearly over the entire sliding length, with the right outer area being more heavily worn. The uncoated tool wears relatively symmetrically, whereby

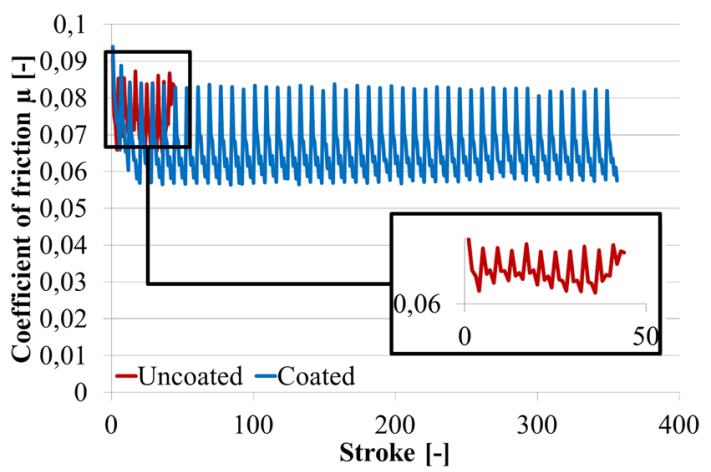

Fig. 10 Coefficient of friction for the uncoated and the coated tool
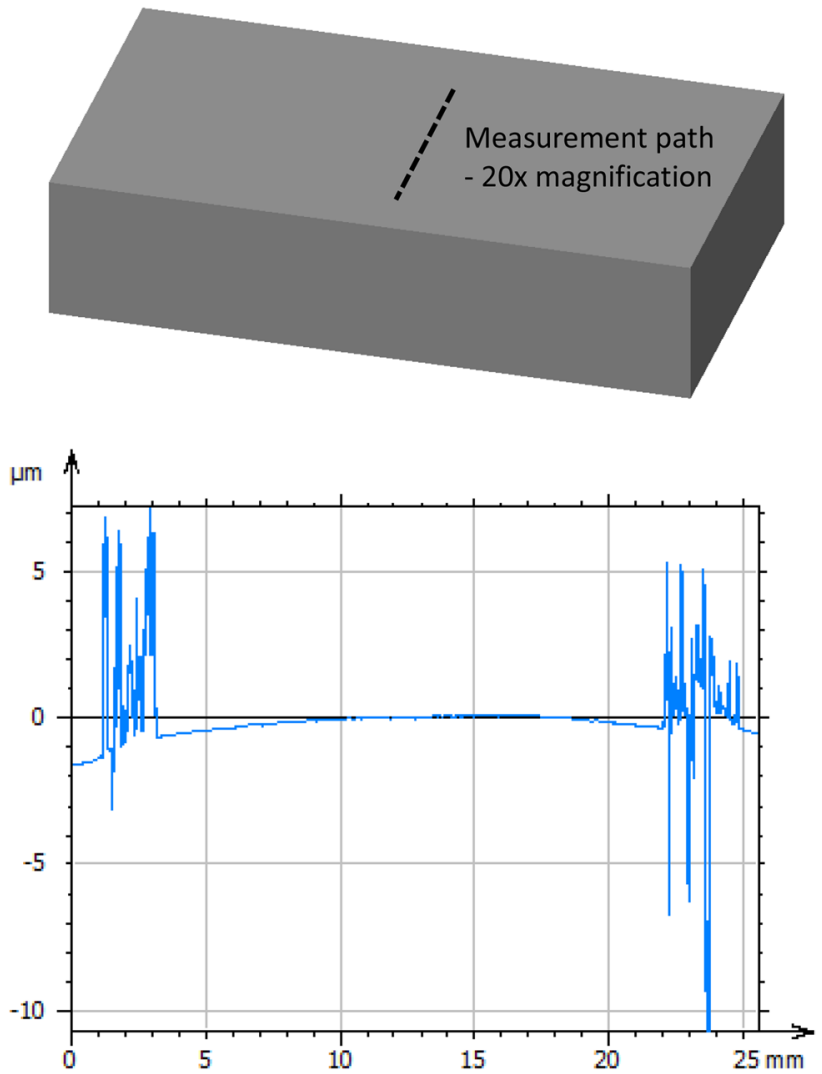

Fig. 11 Confocal measurement of the surface on the uncoated tool (wear on the left and right side of the sliding area). Adhesion is depicted positive, abrasion negative

the outer area of the contact zone between tool and specimen is again most severely worn. As the uncoated plate wears completely parallel, it can be assumed that the compression force is applied symmetrically to the tribological system. The higher rate of wear on one side of the coated plate is therefore due to the variance in wear. The surface of both tools show adhesion and abrasion.

The wear is detected as grooves. In these grooves adhesion can also be partially detected. Figure 9 depicts the evolution of wear over the sliding length. A microscope image is assigned to each data point below. It can be seen that wear occurs much earlier on uncoated tools. In the test with the uncoated tools, the gradient of the groove evolution declines after an initially steep zone and rises again later. In comparison to that, the gradient of the wear increase is reduced drastically with coated tools.

According to Dubar et al., the coefficient of friction can be used as an indicator for wear in cold forging [23].

Figure 10 shows the coefficient of friction for the coated and uncoated tool. The coefficients of friction tend to be higher in the first stroke after each interruption of the test and then decrease. This can be attributed to the temperature 

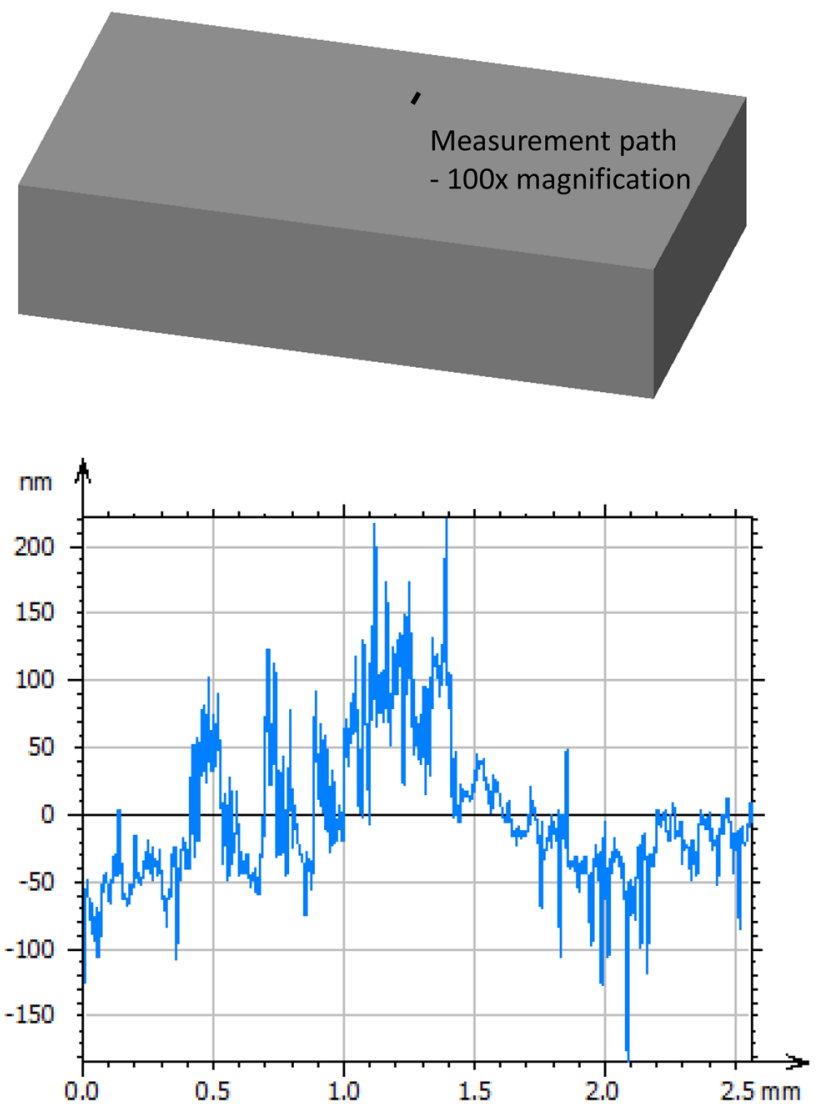

Fig. 12 Confocal measurement of the surface on the coated tool. Adhesion is depicted positive, abrasion negative

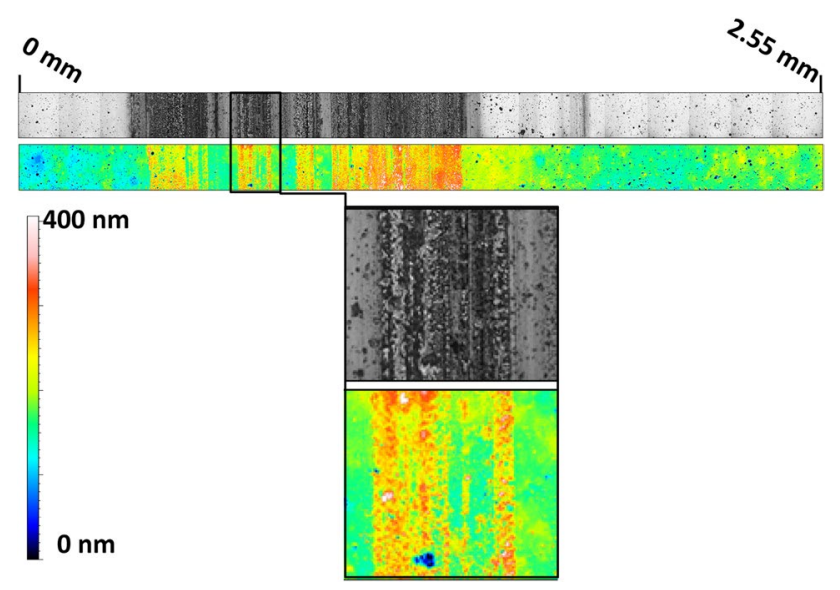

Fig. 13 Comparison of the microscope image and the confocal analysis

in the contact zone, which is lower during the stroke after an interruption.

Tests with the uncoated tool show a higher coefficient of friction. Focused on the lower limit of the scattering range, it can be detected that in the beginning the coefficient of
Table 3 Parameters for the wear simulation

\begin{tabular}{ll}
\hline Parameter & Value \\
\hline Hardness steel surface & $1845 \mathrm{MPa}$ \\
Hardness TiN surface [25] & $2450 \mathrm{MPa}$ \\
Sliding distance & Coated: $10,680 \mathrm{~mm}$ \\
& Uncoated: $1320 \mathrm{~mm}$ \\
Wear depth & Coated: $0.0002 \mathrm{~mm}$ \\
& Uncoated: $0.01 \mathrm{~mm}$ \\
Contact normal stress & $1050 \mathrm{MPa}$ \\
Wear coefficient & $\mathrm{k}_{\text {coated }}=4.3695 \mathrm{E}-08$ \\
& $\mathrm{k}_{\text {uncoated }}=1.3317 \mathrm{E}-05$ \\
\hline
\end{tabular}

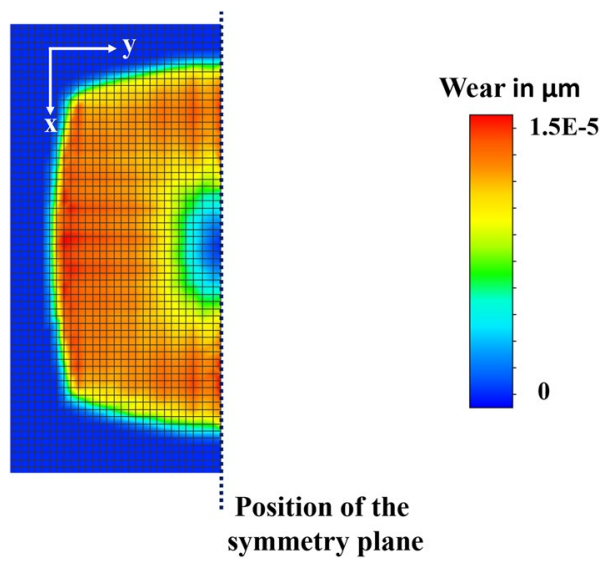

Fig. 14 Simulated wear of the coated tool after step 1. Load applied, sliding length $0 \mathrm{~mm}$

friction increases, then it decreases and rises again at the end. This coincides with the growth of the grooves.

Tests with the coated tools display a similar level of friction. The initial wear for this tool cannot be determined from the coefficients of friction.

The wear is further quantified by confocal microscopic measurements. In particular, its depth is measured. On the coated tool, a depth of $0.1 \mu \mathrm{m}$ can be found. Figure 11 and Fig. 12 show the profile of the surface along the displayed paths for the coated and uncoated tools. Up to $10 \mu \mathrm{m}$ deep wear marks are present on the uncoated tool.

The wear of the coated tool can only be determined with a higher magnification. $\mathrm{A} \times 100$ magnification shows that $200 \mathrm{~nm}$ wear marks are present on the tool. These can be found as material aggregation and as a material removal.

A closer inspection of the confocal measurement of the groove on the coated tool, which was performed for Fig. 12, can be seen in Fig. 13. The figure shows that a change in color of the coating also indicates wear. Brighter areas are less worn out than darker areas. 


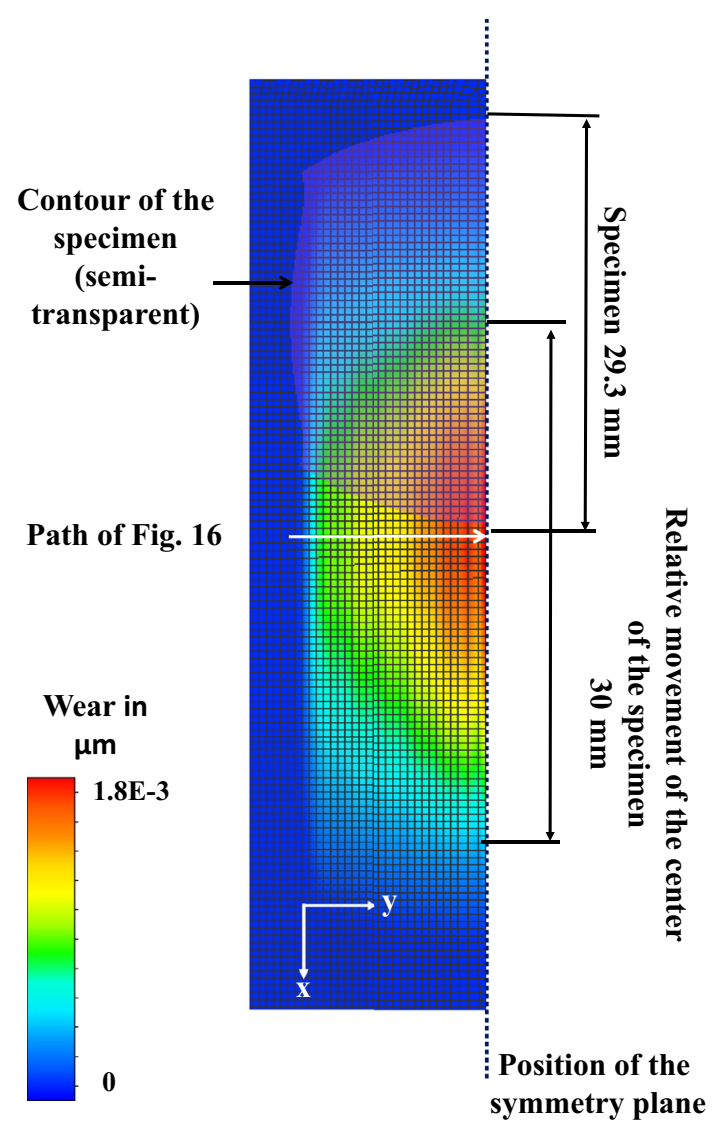

Fig. 15 Simulated wear of the coated tool after step 2. Sliding length: $60 \mathrm{~mm}$ (30 $\mathrm{mm}$ forward- and $30 \mathrm{~mm}$ return stroke)

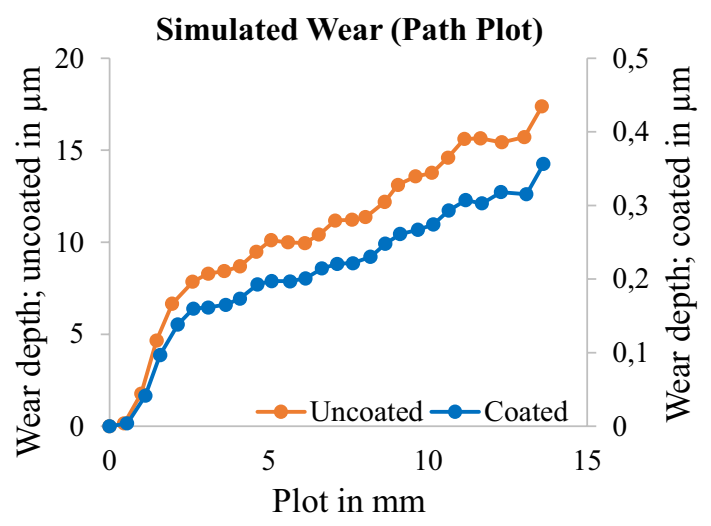

Fig. 16 Path plot of the simulated wear of the coated and uncoated tool after step 2

Based on the experiences with industrial tools (Fig. 4), it can be assumed that first the abrasion takes place and then adhesion occurs on this rough surface of the substrate. It can be assumed that the deepest groove depth represents the initial wear. The resulting adhesion is shown as an positive altitude in the measurement. For the calculation of the $\mathrm{k}$ value, therefore, only the deepest point is considered.

\subsection{Wear Forecast}

Parameters for the wear model are calculated on the basis of the values shown in Table 3. These values are also implemented in simufact.forming 15.0. The determined wear coefficient $\mathrm{k}$ is calculated according to Formula 3 with the parameters for wear depth, as shown in Table 3.

The simulation is carried out in two stages. In the first stage, a specimen is loaded with the process force. The specimen itself has already been formed in another simulation beforehand. After the compression force has been reached, the second stage begins, in which the sliding process (30 mm forward and $30 \mathrm{~mm}$ backward) is carried out.

Figure 14 shows the simulated wear of the specimen on the tool after reaching the compression force. Only the left half of the wear can be seen in the simulation, since the symmetry condition prevails on the right side. As shown in the experiments, the highest wear can be found at the edge of the contact area between the specimen and the tool. Only small deformations occur which result from a nonrelative movement in the center of the sample. According to formula 3 there is nearly no wear predicted. However, wear occurs at a very low level, which is why it is not important for the whole wear after stage 2 .

As shown in Fig. 15, a different condition of the simulated wear appears after step 2 . Wear is decreasing slightly from the center of the contact surface between the specimen and the sliding plate to the outside. Nevertheless, it is relatively homogeneously distributed. This does not correspond to the observations in the experiment.

The distribution of wear in the simulation of uncoated plates is qualitatively identical. Only the amount of wear is different.

\subsection{Validation}

A path plot of the wear depth from the outside to the center of the contact zone, as indicated by the white arrow in Fig. 15, is shown in Fig. 16 for the coated and uncoated tools. The results are multiplied by the number of strokes in the experiment to allow for comparison with the experiments.

As can be seen in Fig. 16, the maximum wear depths of $0.0002 \mathrm{~mm}$ and $0.01 \mathrm{~mm}$, respectively, for the coated and uncoated tool can be detected on average. However, the distribution of the wear does not correspond to the tests. 


\section{Conclusion}

The experiments with coated and uncoated tools allow different conclusions to be made.

As expected, the uncoated tool wears faster under the same load in the experiment. The grooves are distributed symmetrically over the tool surface.

With the coated tool, the wear is significantly lower, grows slower, and is not distributed symmetrically.

This shows that the protective layer delays wear. It also shows that wear contains stochastic factors as it is also known, e.g., from sheet metal forming [24]. Despite identical loads, practically no wear can be measured on the opposite side. Industrial experience shows that many processes have highly variable downtimes. One reason for this is the observed effect of the stochastic distribution of the initial wear of the protective layer, which can be caused by surface imperfections.

By considering the coefficients of friction, it can also be seen that increased friction is an indicator of increased wear in particular.

In the test under consideration, the form of wear occurs as a mixture of adhesive and abrasive wear. Therefore, the absolute height is a suitable value to use for wear prediction. In wear volume measurements, the proportions of wear would partially cancel each other out. In addition, a change in the color of the coating is already a sign of (initial) wear.

Simulation results show that wear can be predicted on average. However, this predicted wear does not apply to its local distribution after stage 2 (sliding). Instead, wear can be seen on the outer areas. This observation corresponds with the gearing process, where wear can be observed at the end of the calibration zone (also at the outer area of the contact area between workpiece and tool).

Due to the fact that the outer area wears out most quickly, there must be phenomena that determine these differences. The contact normal stress in the center of the specimen is higher, as shown in Fig. 7, the stress is not the only cause of the wear at the edge. Rather, the geometric properties play a role. Lubricant pressure cannot be maintained at the outer areas (as a result of geometric shielding). Therefore, no lubrication state can be maintained. The lubricant flows out of the contact zone due to its fluid dynamic property, tribological loads increase, and wear occurs in this area.

Regarding the initial question, it can be summarized that the wear in the laboratory experiment also occurs on the outer areas which are not predicted by the results of the numerical simulation. A solution for this could be that edge areas in the numerical model are fitted with higher wear rates and thus wear can be predicted correctly.

As the outer area of the calibration zone also wears out during the gear forming process, the cause is assumed to be the geometric influence of the edge, since the lubricating condition cannot be maintained in this area. Due to the fact that Archard does not consider the local lubrication condition, the prediction of the simulation cannot be correct.

\section{Outlook}

The results indicate that the lubrication condition should be included in the wear prediction for cold forging. For this purpose, further experiments will be carried out in order to quantify the effect and describe it in an analysis. After that, this adaptation will be implemented in FE codes, e.g., via a subroutine.

Acknowledgements The authors would like to thank the German Research Foundation (DFG Project 1818/56-1) for the support and funding of this project.

Funding Open Access funding enabled and organized by Projekt DEAL.

Open Access This article is licensed under a Creative Commons Attribution 4.0 International License, which permits use, sharing, adaptation, distribution and reproduction in any medium or format, as long as you give appropriate credit to the original author(s) and the source, provide a link to the Creative Commons licence, and indicate if changes were made. The images or other third party material in this article are included in the article's Creative Commons licence, unless indicated otherwise in a credit line to the material. If material is not included in the article's Creative Commons licence and your intended use is not permitted by statutory regulation or exceeds the permitted use, you will need to obtain permission directly from the copyright holder. To view a copy of this licence, visit http://creativecommons.org/licenses/by/4.0/.

\section{References}

1. Doege, E., Behrens, B.: Handbuch der Umformtechnik- Grundlagen, Technologien, Maschinen. Springer, New York (2006)

2. Osakada, K., Mori, K., Altan, T., Groche, P.: Mechanical servo press technology for metal forming. CIRP Anal. 60(2), 651-672 (2011)

3. Maeno, T., Osakada, K., Mori, K.: Reduction of friction in compression of plates by load pulsation. Int. J. Mach. Tools Manuf. 51, 612-617 (2011)

4. Maeno, T., Mori, K., Hori, A.: Application of load pulsation using servo press to plate forging of stainless steel parts. J. Mater. Process. Technol. 214, 1379-1387 (2014)

5. Maeno, T., Mori, K.-I., Ichikawa, Y., Sugawara, M.: Prevention of seizure in inner spline backward extrusion by low-cycle oscillation using servo press. Procedia Eng. 81, 1860-1865 (2014)

6. Matsumoto, R., Hayashi, K., Utsunomiya, H.: Experimental and numerical analysis of friction in high aspect ratio combined forward-backward extrusion with retreat and advance pulse ram motion on a servo press. J. Mater. Process. Technol. 214, 936-944 (2014)

7. Landgrebe, D. et al.: The effect of cushion-ram pulsation on hot stamping. In: Proceedings of the International ESAFORM Conference on Material Forming, at Nantes (2016) 
8. Grupp, P.: Lightweight design innovations in the passenger car gear production. In: Proceedings of the 45th ICFG Plenary Meeting, pp. 130-135 (2012)

9. Groche, P., Heß, B.: Friction control for accurate cold forged parts. CIRP Ann. Manuf. Technol. 63, 285-288 (2014)

10. Schmidt, W., Heß, B., Groche, P.: Investigation of the tribological conditions in forming gears with oscillating ram movements. In: Proceedings of the 7th International Conference on Tribology in Manufacturing (2016)

11. Heß, B.: Präzise Kaltmassiv- umformung für die Herstellung von Verzahnungen mittels oszillierendem Verzahnungseindrücken durch optimierte Reibverhältnisse, Dissertation Technische Universität Darmstadt. Shaker-Verlag (2016)

12. Archard, J.F.: Contact and rubbing of flat surfaces. J. Appl. Phys. 24, 981-989 (1953)

13. Rabinowicz, E.: Friction and Wear of Materials, 2nd edn. Wiley, Hoboken (1995)

14. Holm, R.: Electric contacts. Almquist \& Wiksels Botryckeri, Stockholm (1946)

15. Colaco, R.: Surface-Damage Mechanisms From Nano- and Microcontacts to Wear of Materials. In: Fundamental of Friction and Wear on Nanoscale. Springer, New York (2007)

16. Simufact.Forming 15.0 User Application (2018)

17. Groche, P., Stahlmann, J., Müller, C.: Mechanical conditions in bulk metal forming tribometers - Part two. Tribol. Int. 66, 345351 (2013)
18. Schrader, T., Shirgaokar, M., Altan, T.: A critical evaluation of the double cup extrusion test for selection of cold forging lubricants. J. Mater. Process. Technol. 189, 36-44 (2007)

19. Isogawa, K., Kimura, A., Tazawa, Y.: Proposal of an evaluating method on lubrication. Ann. CIRP 41(1), 262-266 (1992)

20. Kunogi, M.: A new method of cold extrusion. J. Sci. Res. Inst. Tokyo 50, 215-246 (1956)

21. Groche, P., Kramer, P., Bay, N., Christiansen, P., Dubar, L., Hayakawa, K., Hu, C., Kitamura, K., Moreau, P.: Friction coefficients in cold forging - a global perspective. CIRP 67, 261-264 (2018)

22. Müller, C., Jahn, A., Groche, P.: Lubrication of cold forging tools with single layer lubricants. In: Proceedings of the ICFG Plenary Meeting 2013, 31 (2013)

23. Dubar, M., Dubois, A., Dubar, L.: Wear analysis of tools in cold forging: PVD versus CVD TiN coatings. Wear 259, 1109-1116 (2005)

24. Gaard, A.: Wear in sheet metal forming. Karlstad University Studies 2008, 10 (2008)

25. Rauscher, H., Perucca, M., Buyle, G.: Plasma Technology for Hyperfunctional Surfaces. WILEY-VCH, Hoboken 2008, 285 (2010)

Publisher's Note Springer Nature remains neutral with regard to jurisdictional claims in published maps and institutional affiliations. 